\title{
Booklet on Business Records
}

The Business Historical Society has just published a revised edition of the pampllet, 'The Preservation of Business Records, by Ralph M. Hower, assistant professor of Business History at the Harvard Graduate School of Business Administration and clerk of the Business Historical Society. The publication of this new edition has been made possible through the coopperation of the Joint Committee on Materials for Research of the Social Science Research Council. Members will recall that this pamphlet was first issued in 1937 as a regular number of the Bulletin. It has been out of print since shortly after the second printing. The continuing demand for copies from business firms and libraries has made necessary the republication. The author has taken advantage of this opportunity to add new and up-to-date information as well as to incorporate the suggestions of business firms that used the first edition. The present edition has been bound in a cover which is coated to make it washable and durable.

The general format of the pamphlet has been changed to make it more readable and to enable it to be used as a handy reference guide by the business executive who wants to delegate to an assistant the work of administering a program to care for records systematically. It sets up a schedule which most firms can put into effect economically in preserving their most important records.

As before, the Appendix contains a description of the current practices of such firms as an advertising agency, a bank, a department store, two public utilities, a railroad, and several types of manufacturing concerns. To the Appendix has been added a section describing an unusually effective system used by a wellknown telephone company in preserving its records.

The primary purpose of the pamphlet remains the same, namely to answer the following four questions:

1. Why should business records be preserved?

2. What material should be selected for preservation?

3. How should records be preserved?

4. When should preservation be undertaken?

Copies will be sent free to members or others upon application to the Executive Secretary of the Society. 